\title{
Single-operator pancreatoscopy with electro- hydraulic lithotripsy of large pancreatic duct stones in post-Whipple anatomy
}
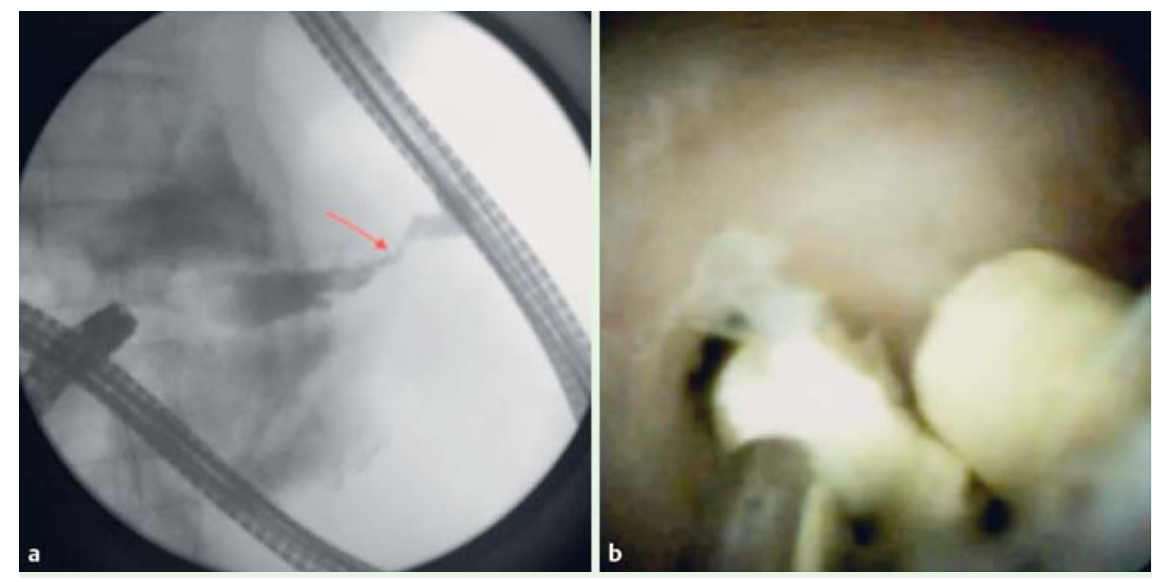

Fig. 1 Imaging and treatment for pancreatitis after Whipple surgery. a Pancreatogram showed a dilated pancreatic duct with a distal stricture (arrow). b Electrohydraulic lithotripsy was performed for fragmentation of pancreatic duct stones.

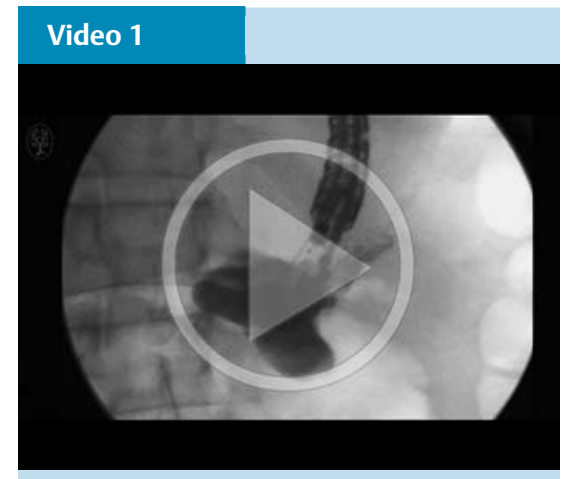

Endoscopic ultrasound-assisted digital pancreatoscopy in post-Whipple anatomy.
A 61-year-old man with chronic, idiopathic pancreatitis previously treated with Whipple surgery was referred for recurrent abdominal pain and dilated main pancreatic duct (MPD) on magnetic resonance imaging. Endoscopic ultrasound (EUS) showed a 9-mm MPD with an abrupt cutoff at the level of the tail, which raised suspicion for a distal stricture and the possibility of a malignancy or main duct intraductal papillary mucinous neoplasm ( Fig. 1).

An enteroscopy-assisted endoscopic retrograde pancreatoscopy was attempted in order to ascertain the nature of this abnormality; however, this was unsuccessful owing to the inability to locate the pancreaticojejunostomy. EUS-assisted rendezvous was therefore performed with pancreatogram to confirm the dilat-

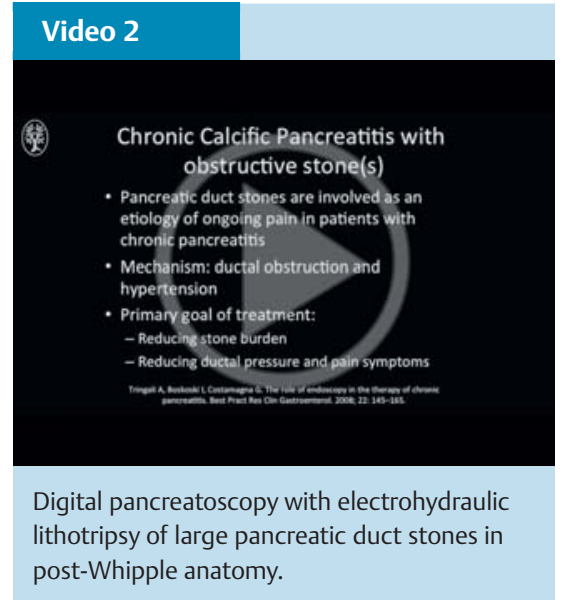

ed MPD and distal stricture ( $\bullet$ Video 1 ). Using a therapeutic gastroscope, pancreatoscopy with a digital single-operator cholangioscope (Spyglass DS; Boston Scientific, Marlborough, Massachusetts, USA) was then undertaken. Unexpectedly, pancreatoscopy revealed several large pancreatic duct stones. The stones were subsequently fragmented using the electrohydraulic lithotripsy (EHL) probe and multiple shockwaves of $50 \mathrm{~W}$, followed by balloon sweeps and pancreatic stent insertion ( $\bullet$ Video 2 ).

The patient did well following the procedure, with significant improvement in pain symptoms, and is currently awaiting a repeat procedure for stent removal and dilation of the distal MPD stricture.

Ductal hypertension from pancreatic duct stones is one of the important etiologies of ongoing pain in patients with chronic pancreatitis [1]. Therefore, the primary goal of treatment when stones are encountered is to reduce the stone burden and ductal pressure. This can be achieved through surgery, extra-corporal shockwave lithotripsy, or pancreatoscopy with EHL. The latter has been shown to be associated with high technical success, clinical response, and a good safety profile [2]. However, performing pancreatoscopy following pancreaticoduodenectomy has not been well described. The current case demonstrates both the potential technical feasibility, when the pancreaticojejunostomy can be reached with a therapeutic gastroscope, and diagnostic benefits of performing digital pancreatoscopy in patients with significant pancreatic duct abnormalities following Whipple surgery.

Endoscopy_UCTN_Code_TTT_1AR_2AI

Competing interests: Dr. Khashab is a consultant for Boston Scientific.

\section{Yen-I Chen, Saowanee Ngamruen- phong, Yamile Haito-Chavez, Majidah Bukhari, Mouen A. Khashab}

Department of Medicine and Division of Gastroenterology and Hepatology, Johns Hopkins Medical Institutions, Baltimore, Maryland, United States

\section{References}

1 Tringali A, Boskoski I, Costamagna G. The role of endoscopy in the therapy of chronic pancreatitis. Best Pract Res Clin Gastroenterol 2008; 22: 145-165

2 Attwell AR, Brauer BC, Chen YK et al. Endoscopic retrograde cholangiopancreatography with per oral pancreatoscopy for calcific chronic pancreatitis using endoscope and catheter-based pancreatoscopes: a 10-year single-center experience. Pancreas 2014; 43: $268-274$

\section{Bibliography}

Dol http://dx.doi.org/

10.1055/s-0042-112979

Endoscopy 2016; 48: E280

(c) Georg Thieme Verlag KG

Stuttgart · New York

ISSN 0013-726X

\section{Corresponding author}

\section{Mouen A. Khashab, MD}

Division of Gastroenterology and Hepatology Johns Hopkins Hospital

1800 Orleans Street, Suite 7125B

Baltimore, MD 21287

United States

Fax: +1-443-683-8335

mkhasha1@jhmi.edu 